\title{
Heckscher-Ohlin revisited: implications of differential population dynamics for trade within an overlapping generations framework
}

\author{
Serdar Sayan* \\ Department of Economics, Bilkent University, 06800 Ankara, Turkey
}

Accepted 31 August 2004

Available online 24 November 2004

\begin{abstract}
This paper investigates the implications of the addition of differential population dynamics to a simple $2 \times 2 \times 2$ model of international trade within an overlapping generations framework. The two regions considered are assumed to be identical in every respect except for the way their populations evolve over time. The effects of these demographic differences are explored by comparing autarky and trade on the basis of (i) the analytical solutions obtained for the steady-state values of key variables and (ii) the paths of these variables plotted using numerical results from simulation experiments carried out under two different demographic scenarios. Unequal population dynamics are shown to affect the relative abundance of the factors of production in each region, giving rise to differentials in wage rates and rentals for capital under autarky conditions. This, in turn, causes costs of production and relative prices to differ, creating the grounds for trade in the sense of Heckscher-Ohlin (HO). Yet, the results reveal that static $\mathrm{HO}$ results cannot be generalized to hold in a dynamic setting where differences in demographics cause factor proportions to evolve independently of trade over time.
\end{abstract}

(C) 2004 Elsevier B.V. All rights reserved.

JEL classification: F11; F43; D58; D91; J10

Keywords: Unequal population dynamics; Heckscher-Ohlin model; International trade; Overlapping generations

\footnotetext{
${ }^{*}$ Tel.: + 903122902071 ; fax: + 903122665140 .

E-mail address: sayan@bilkent.edu.tr (S. Sayan).
} 


\section{Introduction}

The standard 2-country, 2-commodity and 2-factor $(2 \times 2 \times 2)$ Heckscher-Ohlin (HO) model of international trade views the differences in relative factor endowments across countries and differing factor intensities in the production of commodities as the source of comparative advantages. Predicting that trade would generate welfare gains for both parties by creating incentives for more efficient use of resources, this simple model has provided the grounds for a vast number of theoretical and empirical studies. Yet, few studies in the literature have investigated the validity of predictions of the standard $\mathrm{HO}$ model in a dynamic framework possibly because trade between two countries that are identical except for the initial capital/labor ratios would only last until these ratios have been equalized as a result of trade itself (Chen, 1992). Studying dynamic patterns of trade would still be worthwhile, as long as there are differences which would cause factor proportions to evolve independently of trade over time. Differential speed of demographic transition and the resulting differences in population growth rates across countries provide an actually observed example to such differences. Even though some studies in the dynamic trade/growth literature recognized this role of unequal rates of population growth early on (Oniki and Uzawa, 1965; Findlay, 1970; Deardorff, 1987), this issue has not received enough attention in the literature (Sayan, 2002).

Recent demographic projections by the UN (2001) indicate that the effects of unequal population growth rates on trade deserve and are likely to receive more attention from now on. By these projections, the dissimilarities already existing between relative factor endowments of capital-abundant nations (in North America, Europe and East Asia) and the rest of the world are expected to grow in the decades ahead. If the marked differences in the pace of reductions in fertility (and hence, population growth) rates in the relatively capital- and labor-abundant parts of the world are to conform to these projections, not only the labor forces will become more divergent but also greater variations will be observed in the age profiles of populations. Since changes in the age composition of a nation imply additional changes in relative factor endowments (Kenc and Sayan, 2001), demographic differences potentially emerge as major determinants of regional commodity and factor flows.

Exploring the direction and magnitude of likely changes in these flows ahead requires an analytical framework that adds the demographics to the HO model. Even though multi-sector growth models of Oniki and Uzawa (1965) and Findlay (1970) are capable of indicating the directions and magnitude of changes in trade flows in response to changes in capital/labor ratios, they could not show the effects of changes in the age composition of population on relative endowments. To address these, an overlapping generations general equilibrium (OLG-GE) framework would be needed.

In an early attempt in this direction, Fried (1980) used a two-generation OLG-GE model with one factor of production to compare steady-state solutions under free trade and autarky. Buiter (1981), Eaton (1987) and Galor and Lin (1994) also used OLG-GE models to study trade and related issues. Galor and Lin (1997) studied the 
microeconomic foundations of the HO model in an OLG-GE setup by considering two countries with different time preference rates. Later, the two-sector OLG model in Galor (1992) was extended to a two-country setup by Guilló (2001) and Mountford (1998), who studied different implications of a dynamic structure for the HO model. All these studies, however, either completely overlooked possible growth of populations in respective nations or assumed populations growing at identical and constant rates. ${ }^{1}$ Most recently, Jelassi and Sayan (2004) provided closed-form solutions for the long-run trade equilibrium in an $\mathrm{HO}$ model by considering two OLG economies differentiated by constant rates of population growth alone, but their solutions do not allow for the observation of transition paths of variables.

Numerous applied OLG-GE models have also been constructed following Auerbach and Kotlikoff (1987) to investigate the implications of changes in oldage dependency ratios for labor supply, savings and fiscal balances (see Miles, 1999 for a survey). Yet, due possibly to computational difficulties, relatively few studies have extended this framework into multi-country settings. A particularly notable example was INGENUE Team (2001) where international capital flows induced by differential demographic dynamics in six regions of the world are studied. Despite extensive regional coverage of the model, INGENUE researchers considered a single commodity, avoiding the discussion of trade. In a 3-commodity model, Kenc and Sayan (2001) investigated the transmission of the effects of population aging in the EU onto the small, young population economy of Turkey through trade and capital flows.

The purpose of this paper is to investigate the implications of regional differences in population dynamics for trade within a 2-commodity/2-factor OLG framework. For this purpose, the paper considers a two-region $\mathrm{HO}$ world where the consumers in each region have identical preferences over two goods requiring different capital intensities to produce, but with each region using exactly the same technology for the same good. Unlike the static HO model where the regions are distinguished only by their initial capital/labor ratios, we assume that each region is equally well endowed in capital and labor initially, but let relative factor endowments get differentiated across regions over time by introducing regional differences to the way that populations (and hence, labor supplies) grow. In order to capture the additional changes to be observed in relative factor endowments due to the differing speed of population aging, each region is assumed to be populated by two overlapping generations of individuals. The effects of differences in population growth rates on the steady-state values of key variables as well as their paths to the long-run equilibrium are captured through simulation experiments based on two different population growth scenarios repeated under autarky and trade conditions. The first scenario involving gradual disappearance of the initial differences in population growth rates is more realistic but not as tractable analytically as the other one

\footnotetext{
${ }^{1}$ In a study that is notable for its treatment of population growth in an OLG-GE framework, Tosun (2003) considers an economy that is open to capital flows but ignores trade while investigating the effects of demographic transition on fiscal policy formation.
} 
involving constant and distinct growth rates. To the best of our knowledge, this first scenario has never been considered in a similar context in the literature before-for the economywide effects of declining population growth rates in single country setups, see Holtz-Eakin et al. (2004) and Tosun (2003).

The results obtained are generally but not invariably consistent with the static HO framework. As predicted by the static $\mathrm{HO}$ model, the region that becomes relatively better endowed in a factor specializes in the production of (and exports) the commodity requiring more intensive use of that factor. Contrary to those predictions, however, trade would not necessarily lead to welfare gains for both countries and might not even be Pareto superior to autarky. Similar results have previously been obtained with OLG models with stationary populations (Fried, 1980; Galor, 1988; Mountford, 1998), and the findings in this paper add inequalities in the population growth rates to the list of reasons explaining why trade may not improve welfare for both parties in a dynamic setup. They also provide the grounds for a rich discussion on possible consequences of the differential speed of demographic transition in various parts of the world.

The rest of the discussion is organized as follows. The next section sets out the model. Section 3 describes simulation experiments, presents results and discusses their robustness. Section 4 concludes the paper by assessing the implications of results.

\section{The model}

This section first describes the prototype autarky model, and then, the two-region model used to solve for the long-run equilibrium under free trade. Both regions are assumed to produce the same two commodities by employing identical production technologies for each commodity, as in the basic HO model. Likewise, preferences of the corresponding generations are assumed to be the same in both regions. While the initial endowments are also assumed to be the same across regions, relative endowments deviate over time, due to the differences in population dynamics.

\subsection{Prototype autarky model and closed-form solutions}

The model used to describe the long-run autarky equilibrium in each region is an infinite horizon OLG-GE model with perfect foresight. Since the regions considered (regions $A$ and $B$ ) are assumed to be exactly the same in every respect but the population growth characteristics, it would be sufficient to list the assumptions that are common to both regions and write the equations without the superscripts to distinguish them.

Each region is populated by individuals who live for two periods. At an arbitrary period $t$ in time, two types of individuals are alive in each: 'youngs' who were just born and are living the first period of their lives, and 'olds' who were born in the 
previous period and are living the last period of their lives. Each young is assumed to have $(1+n)$ children during the first period of life so that population grows at the rate of $n .^{2}$ Furthermore, the individuals work only when young, each inelastically supplying a fixed amount of labor, and retire in the second period of their lives. Production, exchange and payments are assumed to be made at the end of each period. So, a young born in period $t$ bears children and works in the same period, earning a labor income at the rate of $w_{t}$, and decides how much to consume and how much to save. In period $t+1$, he makes his savings, $A_{t+1}$, available to firms and earns $r_{t+1} A_{t+1}$, where $r_{t+1}$ is the rental rate on capital in period $t+1$. He consumes all of $\left(1+r_{t+1}\right) A_{t+1}$ in period $t+1$, since no intergenerational transfers like bequests are allowed.

Letting $N_{t}$ denote the number of individuals born in period $t$, one can write

$$
N_{t+1}=(1+n) N_{t}
$$

where $n$ denotes the population growth rate.

Within this framework, production and consumption decisions in each economy over $t=0,1, \ldots, s$ as $s \rightarrow \infty$ are characterized as follows:

Production: Two commodities indexed by $i \in\{1,2\}$ are produced by using capital $(K)$ and labor $(L)$ according to constant returns to scale Cobb-Douglas technologies. The parameters of production functions are different across sectors but identical across regions for each sector. Thus, total sectoral outputs at time $t, X_{i t}$, can be expressed in per worker terms as

$$
\begin{aligned}
& x_{1 t}=k_{1 t}^{\alpha} l_{1 t}^{1-\alpha}, \\
& x_{2 t}=k_{2 t}^{\beta} l_{2 t}^{1-\beta},
\end{aligned}
$$

where $x_{1 t}=X_{1 t} / N_{t}$ and $x_{2 t}=X_{2 t} / N_{t} ; k_{i t}=K_{i t} / N_{t}$ is the amount of capital per worker in sector $i$ and $l_{i t}=L_{i t} / N_{t}$ is the amount of labor supplied by each worker in sector $i$. Since total labor supply at time $t, L_{t}$, is given by $L_{t}=N_{t} \bar{l}$, with $\bar{l}$ representing the exogenous level of labor supplied by an individual,

$$
l_{1 t}+l_{2 t}=\bar{l},
$$

which could be normalized to 1 . Similarly, total capital stock in period $t$ is divided between the two sectors yielding in per worker terms

$$
k_{1 t}+k_{2 t}=k_{t} \text {. }
$$

It is assumed that capital stock does not depreciate over time and $\alpha$ is taken to be greater than $\beta, \alpha>\beta$ implies that commodity 1 is the relatively capital-intensive commodity, whereas commodity 2 is labor-intensive. Commodity 1 is assumed to serve both as a consumption good and as capital, whereas commodity 2 is used only for consumption purposes. Furthermore, commodity 1 is taken as the numeraire, and the price of commodity 2 at time $t$ is denoted by $p_{t}$.

\footnotetext{
${ }^{2}$ The assumption of constant population growth will be relaxed later.
} 
The production sectors are assumed to be competitive so that the representative firm producing commodity 1 maximizes profits, $\pi_{1 t}$, by solving the problem

$$
\begin{aligned}
\max _{k_{1 t}, l_{1 t}} & \pi_{1 t}=k_{1 t}^{\alpha} l_{1 t}^{1-\alpha}-r_{t} k_{1 t}-w_{t} l_{1 t} \\
\text { s.t. } & k_{1 t} \geqslant 0, \quad l_{1 t} \geqslant 0 .
\end{aligned}
$$

First-order conditions for (6) and the corresponding problem for the representative firm producing commodity 2 yield the following expressions for sectoral demands for factors of production:

$$
\begin{aligned}
& l_{1 t}=\frac{\delta-k_{t} p_{t}^{1 /(\beta-\alpha)}}{\delta-\varepsilon}, \\
& l_{2 t}=\frac{-\varepsilon+k_{t} p_{t}^{1 /(\beta-\alpha)}}{\delta-\varepsilon}, \\
& k_{1 t}=\frac{-\varepsilon k_{t}+\delta \varepsilon p_{t}^{1 /(\alpha-\beta)}}{\delta-\varepsilon}, \\
& k_{2 t}=\frac{\delta k_{t}-\delta \varepsilon p_{t}^{1 /(\alpha-\beta)}}{\delta-\varepsilon},
\end{aligned}
$$

where

$$
\delta=\left(\frac{\beta}{\alpha}\right)^{\alpha /(\alpha-\beta)}\left(\frac{1-\beta}{1-\alpha}\right)^{(1-\alpha) /(\alpha-\beta)}
$$

and

$$
\varepsilon=\left(\frac{\beta}{\alpha}\right)^{\beta /(\alpha-\beta)}\left(\frac{1-\beta}{1-\alpha}\right)^{(1-\beta) /(\alpha-\beta)},
$$

along with the following expressions for factor rental rates:

$$
\begin{aligned}
& r_{t}=\alpha k_{1 t}^{\alpha-1} l_{1 t}^{1-\alpha}=p_{t} \beta k_{2 t}^{\beta-1} l_{2 t}^{1-\beta}, \\
& w_{t}=(1-\alpha) k_{1 t}^{\alpha} l_{1 t}^{-\alpha}=p_{t}(1-\beta) k_{2 t}^{\beta} l_{2 t}^{-\beta} .
\end{aligned}
$$

Consumption: An individual born at time $t$ has a utility function of the form $u_{t}=C_{t}^{\mu} C_{t+1}^{1-\mu}$, where $C_{t}=C_{1 y t}^{\theta} C_{2 y t}^{1-\theta}$ denotes the utility gained from consumption when young and $C_{t+1}=C_{1 o t+1}^{\theta} C_{2 o t+1}^{1-\theta}$ denotes the utility gained from consumption when old. Thus, $C_{i y t}$ denotes the amount of commodity $i$ consumed when young, and $C_{i o t+1}$ denotes the amount of commodity $i$ consumed when old, all in per capita terms. The representative individual makes consumption decisions by solving the following problem:

$$
\begin{aligned}
\max _{C_{1 y t}, C_{2 y t}, C_{1 o t+1}, C_{2 o t+1}} & u_{t} \\
\text { s.t. } & C_{1 y t}+p_{t} C_{2 y t}+\frac{C_{1 o t+1}+p_{t+1} C_{2 o t+1}}{1+r_{t+1}}=w_{t},
\end{aligned}
$$


where $r_{t+1}$ is the rationally anticipated return to capital in period $t+1$ and $p_{t+1}$ is the rationally anticipated price of commodity 2 in period $t+1$. The solution of this problem yields the following expressions for sectoral consumptions by generations:

$$
\begin{aligned}
& C_{1 y t}=\mu \theta w_{t}, \\
& C_{2 y t}=\mu(1-\theta) \frac{w_{t}}{p_{t}}, \\
& C_{1 o t+1}=(1-\mu) \theta\left(1+r_{t+1}\right) w_{t} \text { for } t=0,1,2, \ldots, s-1, \\
& C_{2 o t+1}=(1-\mu)(1-\theta)\left(1+r_{t+1}\right) \frac{w_{t}}{p_{t+1}} \text { for } t=0,1,2, \ldots, s-1 .
\end{aligned}
$$

Furthermore, the following conditions are required to make sure that the initial period consumption of old agents (who would normally finance their consumption out of previous period's savings) is compatible with the initial conditions for each sector:

$$
C_{i o 0}=(1+n)\left(x_{i 0}-C_{i y 0}\right) .
$$

Equilibrium conditions: Since olds consume all their wealth in the current period, only capital transferred to the next period is the savings of the current young, implying that

$$
K_{t+1}=\left(w_{t}-C_{1 y t}-p_{t} C_{2 y t}\right) N_{t} \quad \text { for } t=0,1,2, \ldots, s-1,
$$

which can equivalently be expressed in per worker terms by dividing both sides of (18a) through $N_{t+1}$ and remembering (14) and (15) as

$$
k_{t+1}=\frac{(1-\mu) w_{t}}{1+n} \quad \text { for } t=0,1,2, \ldots, s-1 .
$$

Dynamic equilibrium requires the clearance of goods' markets in each period $t$ so that

$$
\begin{aligned}
& X_{1 t}=N_{t} C_{1 y t}+N_{t-1} C_{1 o t}+\left(K_{t+1}-K_{t}\right), \\
& X_{2 t}=N_{t} C_{2 y t}+N_{t-1} C_{2 o t} .
\end{aligned}
$$

Since Eqs. (19) and (20) imply each other by Walras' Law, one of them can be dropped and commodity market equilibrium can be captured by reexpressing Eq. (20) in per capita terms as follows:

$$
x_{2 t}=C_{2 y t}+\frac{C_{2 o t}}{1+n}=\frac{\mu(1-\theta) w_{t}}{p_{t}}+\frac{(1-\mu)(1-\theta) w_{t-1}}{(1+n) p_{t}}\left(1+r_{t}\right)
$$

$$
\text { for } t=1,2, \ldots, s \text {. }
$$

A perfect foresight equilibrium can now be defined formally as a sequence of relative price-capital stock per worker pairs $\left\{k_{t}, p_{t}\right\}_{t=0}^{s}$ with $s \rightarrow \infty$ at which:

- firms maximize profits at every period $t$ by employing $k_{i t}$ units of capital (Eqs. (9) and (10)) at the perfectly competitive rental rate $r_{t}$ (one of the equations in (12)) 
and $l_{i t}$ units of labor (Eqs. (7) and (8)) at the perfectly competitive wage rate $w_{t}$ (one of the equations in (13)) to produce sectoral outputs (Eqs. (2) and (3)),

- the utilities of young and old agents are maximized at every period $t$ with sectoral consumptions given by Eqs. (14)-(17),

- the market for good 2 is cleared at every period $t$ (Eq. (21)) with the clearance of the other market assured by Walras' Law, while

- the dynamics of capital stock at time $t+1$ is satisfied for all $t$ (Eq. (18b)).

The equations referred above are needed together to numerically determine the time paths of sectoral outputs, $x_{i}$; sectoral employment of capital and labor, $k_{i}$ and $l_{i}$; economywide capital stock per worker, $k$; factor rentals, $w$ and $r$; relative price ratio, $p$; and sectoral per capita consumptions by generation, $C_{i y}$ and $C_{i o}$, with each path having $s+1$ values for $t=0, \ldots, s$, amounting to $14(s+$ 1) individual values to be determined. Considering the lagged nature of the relationship between capital stock per worker and the wage rate in Eq. (18b), and the appearance of $w_{t-1}$ in (21), the number of equations will only be $14 s+12$, requiring that the initial values of sectoral capital stocks per capita $\left(k_{10}\right.$ and $\left.k_{20}\right)$ be fixed. ${ }^{3}$

It has been shown by Jelassi and Sayan $(2003,2004)$ that the steady-state value of the relative price ratio, satisfying $p_{t}=p_{t-1}=p_{s}>0$, exists and is unique for any given values of $\alpha, \beta, \mu, \theta$ between 0 and 1 , and $n \geqslant 0$. Given the difference equation that could be derived to match the path of $p_{t}$ to that of $k_{t+1}$, the steady-state values of $k$ and other variables can be solved. The resulting expressions can then be differentiated with respect to $n$ to observe the effects of population growth on the long-run autarky values of key variables which, in turn, will reveal the direction of trade to occur between two economies with different population growth rates when they become trade partners. As shown by Jelassi and Sayan (2003), this differentiation yields

$$
\frac{\partial k_{s}}{\partial n}<0, \quad \frac{\partial w_{s}}{\partial n}<0, \quad \frac{\partial r_{s}}{\partial n}<0 \text { and } \frac{\partial p_{s}}{\partial n}= \begin{cases}<0 & \text { for } \alpha>\beta, \\ >0 & \text { for } \alpha<\beta .\end{cases}
$$

These results unambiguously establish, concerning two OLG economies that are identical in every respect (including the initial factor endowments) but their population growth rates, that the economy with the lower (higher) population growth rate

(i) will end up with a higher (lower) per capita capital stock at the steady state, ${ }^{4}$ and hence, will become relatively capital-abundant (labor-abundant),

(ii) will have a higher (lower) wage rate at the steady state, and hence, will have a relative cost advantage in the production of capital-intensive (labor-intensive) commodity,

\footnotetext{
${ }^{3} \mathrm{~A}$ code for the solution of this model is available upon request.

${ }^{4}$ This result is consistent with those previously obtained from conventional growth models (e.g., Solow, 1956), as well as OLG models (Diamond, 1965).
} 
(iii) will have a lower (higher) rental rate at the steady state, and hence, will have a relative cost advantage in the production of capital-intensive (labor-intensive) commodity, and

(iv) may have a lower or higher relative price for commodity 2 (in terms of commodity 1) depending upon the relative magnitudes of $\alpha$ and $\beta$-or, depending upon whether commodity 2 is relatively capital-intensive $(\alpha<\beta)$ or labor-intensive $(\alpha>\beta)$-in general.

Since $\alpha$ is taken to be greater than $\beta$ to let the commodity that serves only as a consumption good (commodity 2) be the labor-intensive commodity here, (iv) above reveals that the region with a lower (higher) population growth rate will have a higher (lower) relative price for commodity 2 at the steady state. In the light of (i)-(iii), the labor-abundant region must be expected to have a comparative advantage in the production of the labor-intensive commodity.

The inferences (i)-(iv) made from the inequalities in (22) are qualitatively similar to the conditions set forth by the static HO model for two autarkic economies to enjoy mutual welfare gains from trade. Yet, these inequalities alone do not reveal anything about the welfare consequences of trade for the parties involved. Investigation of welfare consequences requires evaluation of the partial derivatives of consumption variables $C_{i y t}$ and $C_{i o t+1}$ with respect to the population growth rate under trade. However, closed-form solutions obtained for the steady-state values under autarky offer hints concerning the ambiguous nature of possible welfare results. By these closed-from solutions, $\partial c_{i y} / \partial n$ is unambiguously negative for $\forall i$ at the steady state, but the same is not true for consumption of commodities 1 and 2 by the older generations (Jelassi and Sayan, 2003). That is,

$$
\begin{aligned}
& \frac{\partial c_{1 o s}}{\partial n}= \begin{cases}<0 & \text { for } \alpha+(2 \alpha-1) r_{s}>0, \\
>0 & \text { for } \alpha+(2 \alpha-1) r_{s}<0,\end{cases} \\
& \frac{\partial c_{2 o s}}{\partial n}= \begin{cases}<0 & \text { for } \beta+(\beta+\alpha-1) r_{s}>0, \\
>0 & \text { for } \beta+(\beta+\alpha-1) r_{s}<0 .\end{cases}
\end{aligned}
$$

The inequalities in (23) imply that the region to enjoy a higher utility under autarky will depend on the values of production parameters, and the steady-state value of the interest rate-which is determined by the entire set of system parameters itself (Jelassi and Sayan, 2003). Furthermore, one would expect trade to lead to a common value for $r_{s}$ lying between steady-state autarky values to be observed in each of the low- and high-population growth economies. Given (23), such a tradeinduced change in $r_{s}$ may lead to an improvement as well as a deterioration in welfare relative to the autarky as previously suggested by Fried (1980) and Galor (1988). ${ }^{5}$ In fact, solution of the trade model in Jelassi and Sayan (2004) confirms this intuition, indicating that the signs of $\partial c_{i o s} / \partial n$ will remain ambiguous as far as the

\footnotetext{
${ }^{5}$ Mountford (1998) also showed how the addition of a dynamic OLG structure to the standard convex $2 \times 2 \times 2 \mathrm{HO}$ model can reverse the static implications of international trade in the long-run.
} 
long-run equilibrium under trade is concerned. The simulations carried out with the model described in the next section produce further evidence that trade may lead to a deterioration in the welfare of low-population growth region, by also showing the paths of key variables to the steady state.

\subsection{Trade}

Letting regions $A$ and $B$ become partners in trade requires developing a twocountry trade model. In this section, the low-(high-)population growth region is assumed to be $A(B)$, and region-specific variables are tagged $A$ and $B$ in superscripts.

A natural result of free trade will be the equalization of (relative) prices in both regions in each period so that

$$
p_{t}^{A}=p_{t}^{B} .
$$

In this setup, even when both regions start with the same initial populations and endowments of capital and labor, differences in population growth rates, $n^{A}$ and $n^{B}\left(n^{A}<n^{B}\right)$, will let country $A(B)$ become the relatively capital-(labor-)abundant region immediately after the first period. This is because of two reasons. First, the labor supply in region $B$ increases faster than in country $A$. Secondly, since only the youngs are allowed to bear children, the share of youngs in the entire population of region $B$ exceeds that in country $A$ after the first period. This, in turn, implies that a greater (smaller) portion of the population in $A(B)$ contributes to the capital accumulation process. As a result of this change in relative endowments, region $A$ must be expected to export the relatively more capital-intensive commodity 1 , while the labor-abundant region (region $B$ ) exporting the relatively more labor-intensive commodity 2. Then, the market clearing conditions in each region under autarky must now be replaced with the condition that the worldwide demand for each commodity is equal to the worldwide supply. This requires that the amount of commodity 1 (commodity 2) that region $A$ exports (imports) be equal to the amount of commodity 1 (commodity 2 ) that region $B$ imports (exports), or that the following equations hold-instead of Eqs. (19) and (20) of the autarky model:

$$
\begin{aligned}
& X_{1 t}^{A}+K_{t}^{A}-K_{t+1}^{A}-N_{t}^{A} C_{1 y t}^{A}-N_{t-1}^{A} C_{1 o t}^{A} \\
& \quad=N_{t}^{B} C_{1 y t}^{B}+N_{t-1}^{B} C_{1 o t}^{B}+K_{t+1}^{B}-K_{t}^{B}-X_{1 t}^{B}, \\
& X_{2 t}^{A}-N_{t}^{A} C_{2 y t}^{A}-N_{t-1}^{A} C_{2 o t}^{A}=N_{t}^{B} C_{2 y t}^{B}+N_{t-1}^{B} C_{2 o t}^{B}-X_{2 t}^{B},
\end{aligned}
$$

where $N_{t}^{A}=\left(1+n^{A}\right) N_{t-1}^{A}$ and $N_{t}^{B}=\left(1+n^{B}\right) N_{t-1}^{B}$.

Formulated as such, the model does not directly allow for foreign direct investment and factor movements between regions. However, given that commodity 1 is used for both consumption and investment purposes, capital stock at time $t$ comes from commodity 1 produced at time $t-1$. Therefore, while the installed capital itself is immobile between countries, some of commodity 1 exported by region 
$A$ in the previous period may be used as capital by the importing region $B$ in the current period. ${ }^{6}$

\section{Simulation scenarios and results}

\subsection{Scenarios and the simulation strategy}

In order to observe the paths that endogenous variables would follow over time, the autarky and trade models described above have been simulated under two different demographic scenarios: under the first scenario, population growth rates, $n_{t}^{A}$ and $n_{t}^{B}$, were allowed to start with different initial values and decline at differing speeds across countries, whereas the second scenario considered distinct but constant population growth rates for each region, i.e., $n_{t}^{A}=n^{A} \neq n^{B}=n_{t}^{B} \forall t$. The 1950 values of average population growth rates for 'more-developed regions' and 'less-developed regions, according to the classification of UN (2001) were allowed to serve as the respective initial rates for regions $A$ and $B$. The first scenario is obviously the more realistic one here. Even though the assumption that the population growth rates will remain constant over time is not consistent with empirical observations, the second scenario was retained for it produces better visibility for observation of the effects of differences in population growth rates.

Simulation of the autarky and trade models requires that a set of common values be chosen for production and utility parameters, and the initial values of sectoral capital stock per capita $\left(k_{10}\right.$ and $\left.k_{20}\right)$ that are common to both regions be specified. The simulation strategy adopted here was to start by solving the autarky model under common production and utility parameters selected, and with zero population growth. The resulting steady-state values of $k_{1 t}$ and $k_{2 t}$ were then fed as the initial values, and region-specific autarky models and the trade model were solved again under each demographic scenario. The assumed rates of reductions in the speed of population growth under Scenario 1 were decided through an iterative process in such a way to allow the population growth rate of region $A(B)$ that is declining less rapidly (faster) to reach 0 concurrently with (two periods before) asymptotic convergence to the steady-state under trade. This iterative process used also assured that the number of periods required for steady state to be reached remains the same across all solutions obtained under autarky and trade with each demographic scenario. Table 1 shows assumed characteristics of population dynamics as well as the selected configuration of parameters and other initial conditions used in simulations.

As noted before, production function parameters common to both regions were picked to make production of commodity 1 (consumption-investment good)

\footnotetext{
${ }^{6}$ Market clearance conditions in (19) together with the requirement that amount of commodity 1 exports by country $A$ be equal to imports by country $B$ rule out the possibility of zero consumption in either country when $K_{t+1}>K_{t}$.
} 
Table 1

Initial conditions and parameters used in simulations

\begin{tabular}{|c|c|c|c|c|c|c|c|c|c|}
\hline \multicolumn{2}{|c|}{$\begin{array}{l}\text { Production } \\
\text { parameters }\end{array}$} & \multicolumn{2}{|c|}{$\begin{array}{l}\text { Utility } \\
\text { parameters }\end{array}$} & \multicolumn{2}{|c|}{$\begin{array}{l}\text { Initial pop. of } \\
\text { youngs }\end{array}$} & \multicolumn{2}{|l|}{$\begin{array}{l}\text { Population growth rates } \\
\text { Scenario } 1\end{array}$} & \multicolumn{2}{|l|}{ Scenario 2} \\
\hline$\alpha$ & $\beta$ & $\theta$ & $\mu$ & $N_{0}^{A}$ & $N_{0}^{B}$ & $n_{t}^{A}$ & $n_{t}^{B}$ & $n_{t}^{A}$ & $n_{t}^{B}$ \\
\hline 0.60 & 0.30 & 0.40 & 0.75 & 1 & 1 & $\begin{array}{l}n_{0}^{A}=0.0120 \text { and } \\
n_{t}^{A}=0.5872 n_{t-1}^{A} \quad \text { for } t>0\end{array}$ & $\begin{array}{l}n_{0}^{B}=0.0205 \text { and } \\
n_{t}^{B}=0.6258 n_{t-1}^{B} \text { for } t>0\end{array}$ & $\begin{array}{l}0.0120 \text { for } \\
\text { all } t\end{array}$ & $\begin{array}{l}0.0205 \text { for } \\
\text { all } t\end{array}$ \\
\hline
\end{tabular}


relatively capital-intensive, and that of commodity 2 (serving as a consumption good alone) labor-intensive.

$\theta$ and $\mu$ parameters describing consumers' preferences are also common to both regions as in the standard HO model. It can be shown that $\mu$ represents the youngs' marginal propensity to consume out of labor income, and $\theta$ represents the relative share of first commodity in total consumption spending of the older generation. The value picked for $\mu$ implies a saving rate of $25 \%$, whereas the value picked for $\theta$ implies that the older generation devote $60 \%$ of their consumption expenditures to the commodity that serves solely as a consumer good. Given that the model does not allow for bequests, the values of both parameters ought to be reasonably realistic.

\subsection{Results}

Both regions start with an initial young population of 1 . Since the initial growth rate of population is higher in region $B$ under both demographic simulation scenarios, populations begin to diverge after the first period, causing the labor supply in $B$ to exceed that in $A$ (Fig. 1) and total population share of the unproductive elderly in region $B$ to remain lower than that in region $A$ (Fig. 2).

The result is a gradual change in relative factor endowments (and hence, relative commodity and factor prices) that last until the growth rates of all variables have stabilized (with changes at smaller magnitudes than $10 \mathrm{e}-6$ ) at the end of the 11 th

Working Population in A and B: Scenario 1 (Declining $\mathrm{n}$ )
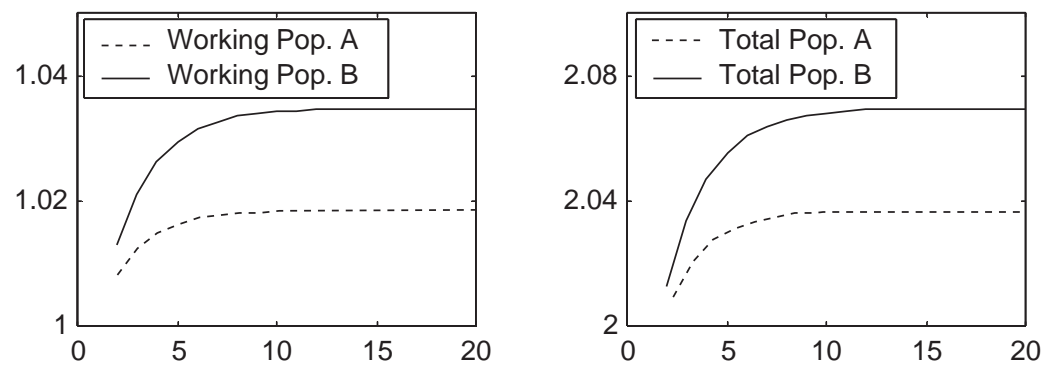

Working Population in A and B: Scenario 2 (Constant $n$ )
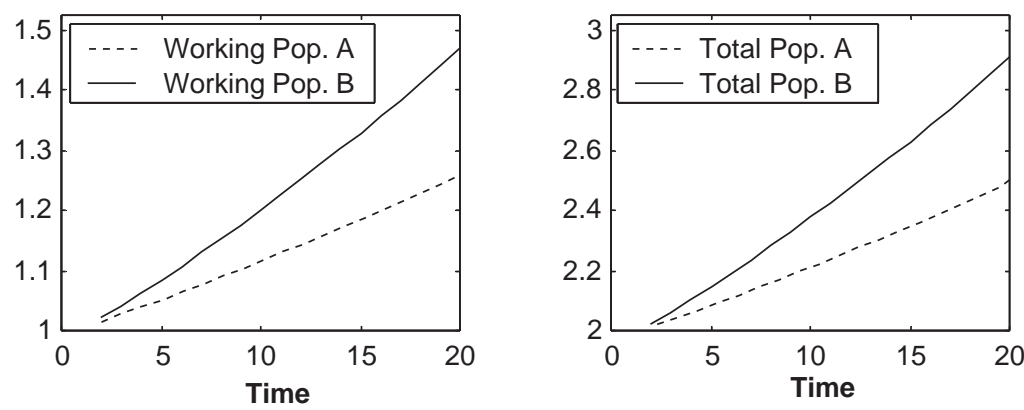

Fig. 1. Population composition by regions. 


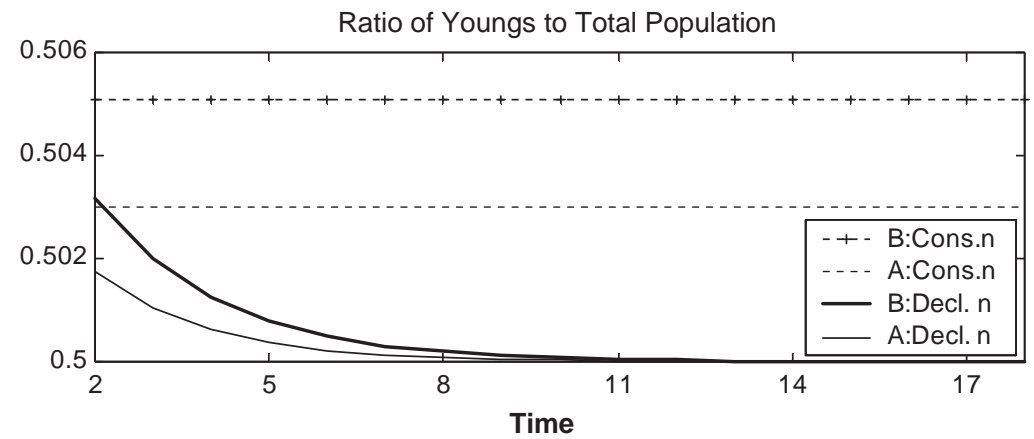

Fig. 2. The share of working youngs in total population.

Per Capita Capital Stock in A and B under Autarky: Scenario1

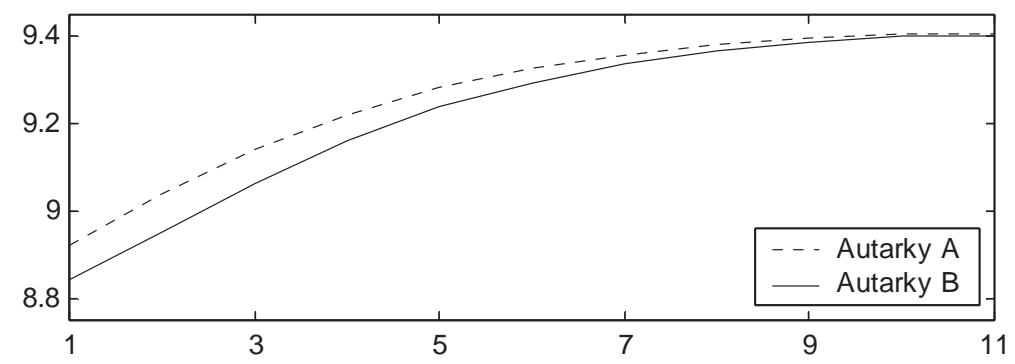

Per Capita Capital Stock in A and B under Autarky: Scenario 2

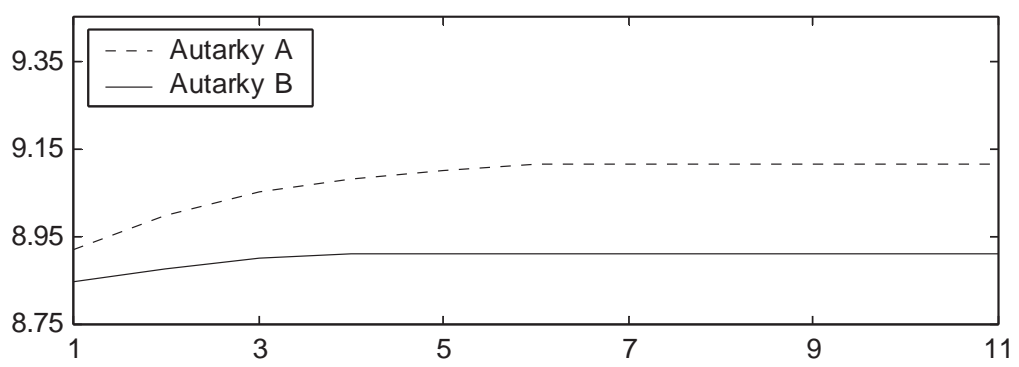

Fig. 3. Per capita capital stock values under autarky over time.

period. The change in relative factor endowments can be observed through the developments in $k_{t}$. Fig. 3 depicts the behavior of $k_{t}$ in both regions under autarky, and shows that the faster population growth in $B$ causes the autarky value of capital per worker in $A$ to exceed that in $B$ immediately after the initial period, and to remain higher thereafter-even though the difference gets smaller towards steady state under Scenario 1 which allows for the differences in population growth rates to be gradually eliminated over time.

As region $B(A)$ becomes relatively labor-(capital-)abundant, factor prices under autarky will begin to reflect the relative abundance of each factor. Consistently with 
the relative scarcity of labor in region $A$, the autarky wage rate in this region lies above that in region $B$ under both demographic scenarios (the upper panel of Fig. 4). Similarly, the relative abundance of capital in $A$ causes the autarky rental rate in this region to stay lower than that in $B$ (the lower panel of Fig. 4 ). In the cases of both wage rates and rental rates, the differences that are distinctly observable under Scenario 2 (the right-hand side plots in Fig. 4) gradually disappear along with the shrinking difference in the population growth rates under Scenario 1.

The differences in factor prices under autarky lead to differences in production costs despite identical technologies employed for each commodity across regions, giving way to relative price differences under autarky conditions. In fact, the autarky relative price of labor-intensive commodity (commodity 2 ) in region $B$ initially stays below that in region $A$ under both demographic assumptions. While the differences in the autarky relative price ratios remain marked throughout all periods under Scenario 2, they begin to converge to each other as population growth rate differences are gradually eliminated under Scenario 1 (Fig. 5).

The differences in autarky relative prices create incentives for trade. Clearly, the capital-abundant (labor-abundant) region $A(B)$ has a cost advantage in the capitalintensive (labor-intensive) commodity as argued before. Following the opening of trade, each region begins to devote more of its resources to the production of the commodity it produces more efficiently so as to take advantage of the relative price differences, becoming even more efficient and reaching a higher productivity as

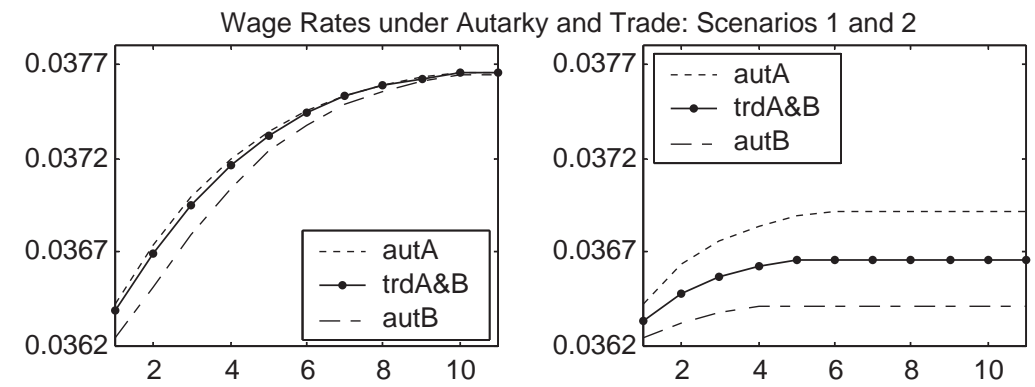

Rental Rates under Autarky and Trade: Scenarios 1 and 2
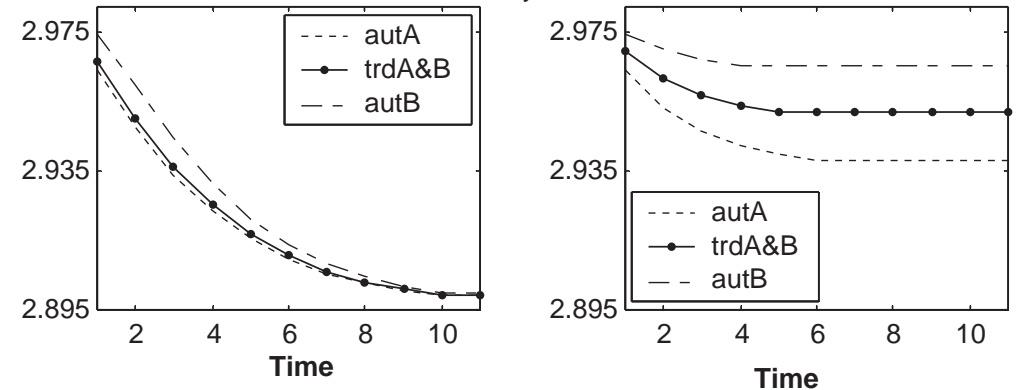

Fig. 4. Wage and rental rates under autarky and trade: Scenario 1 (on the left) and Scenario 2 (on the right). 
Relative Price of Commodity 2 under Autarky and Trade: Scenario 1

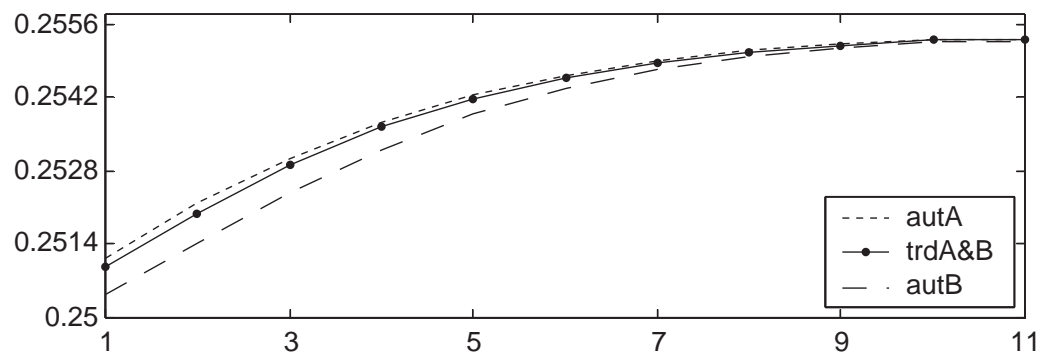

Relative Price of Commodity 2 under Autarky and Trade: Scenario 2

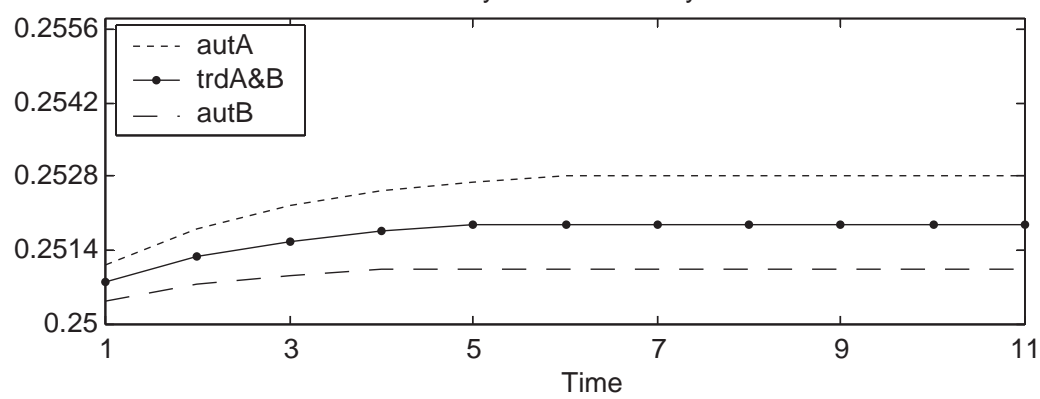

Fig. 5. Relative prices under autarky and trade.

compared to autarky (Fig. 6a). This productivity advantage is maintained during trade (Fig. 6b) under both demographic scenarios-at least until the steady-state under Scenario 1 which allows for the differences in population growth rates to be gradually eliminated over time.

As each region specializes in the production of commodity it produces more efficiently and exports it to the other, the difference between autarky relative prices would be eliminated. So, trade would establish a common relative price ratio and factor prices, just as in the $\mathrm{HO}$ model. These prices stay strictly between the corresponding autarky values throughout all periods under Scenario 2, whereas they supply the values to which autarky prices would converge in the steady state under Scenario 1 (Figs. 4 and 5).

Since trade allows region $B$ to import capital through the imports of capitalintensive investment good exported by the capital-abundant $A$, the amount of capital per worker in $A(B)$ falls below (jumps above) the autarky level after the opening of trade. At the steady state, each worker in region $A(B)$ ends up with a long-run capital stock that is lower (higher) than he would have under autarky with Scenario 2. While the plots produced under this scenario provide for greater visibility, the differences between $k_{t}^{A}$ and $k_{t}^{B}$ would be much smaller under Scenario 1, getting almost totally eliminated by the time steady state has been reached and population growth rate differences have disappeared (Fig. 7). 
Per Capita Output of Sector 1 in A under Autarky \& Trade: Scenarios 1 and 2
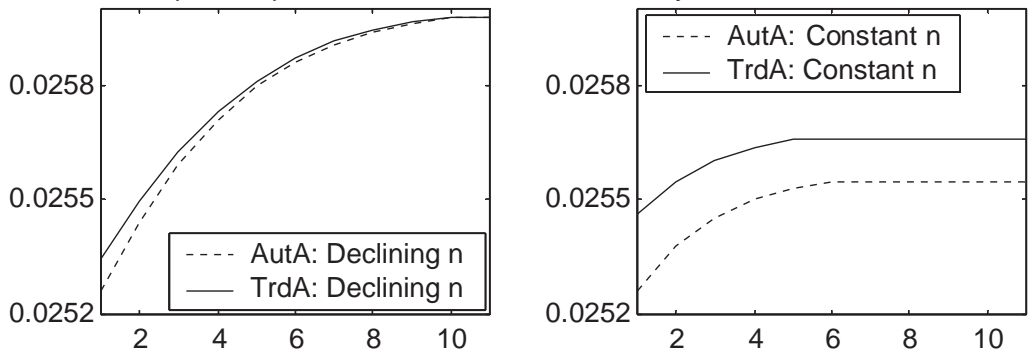

Per Capita Output of Sector 2 in B under Autarky \& Trade: Scenarios 1 and 2

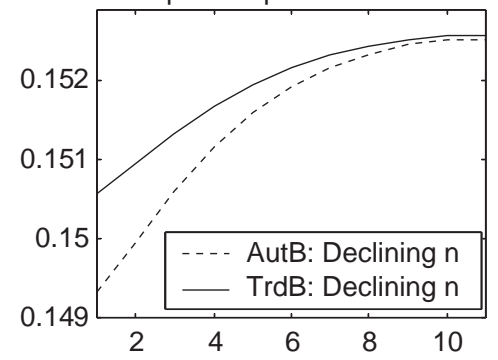

(a)

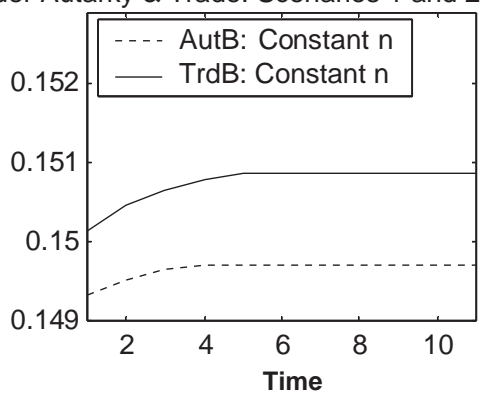

Per Capita Output of Sector 1 under Trade: Scenarios 1 and 2
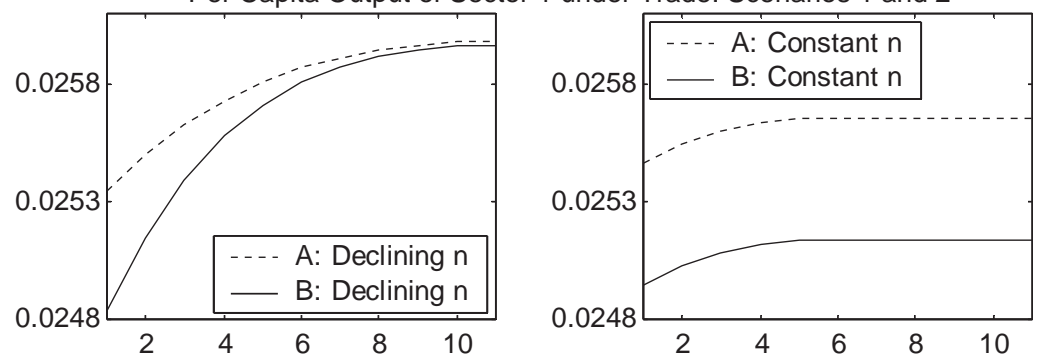

Per Capita Output of Sector 2 under Trade: Scenarios 1 and 2
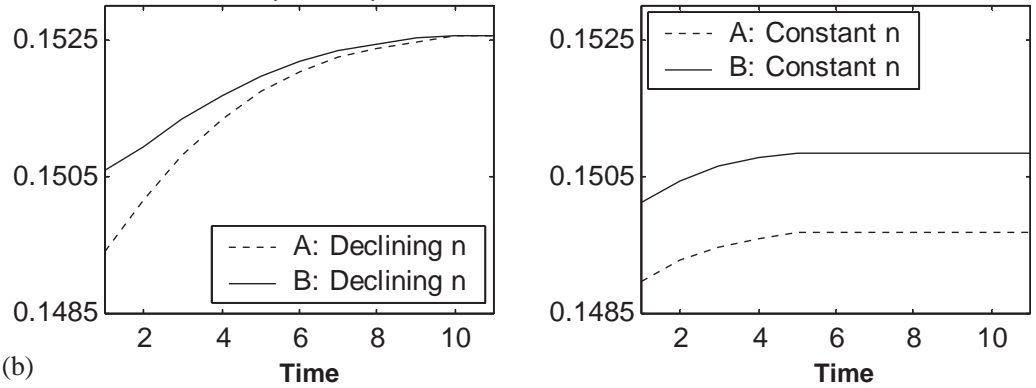

Fig. 6. (a, b) Sectoral productivity of labor under autarky and trade. 

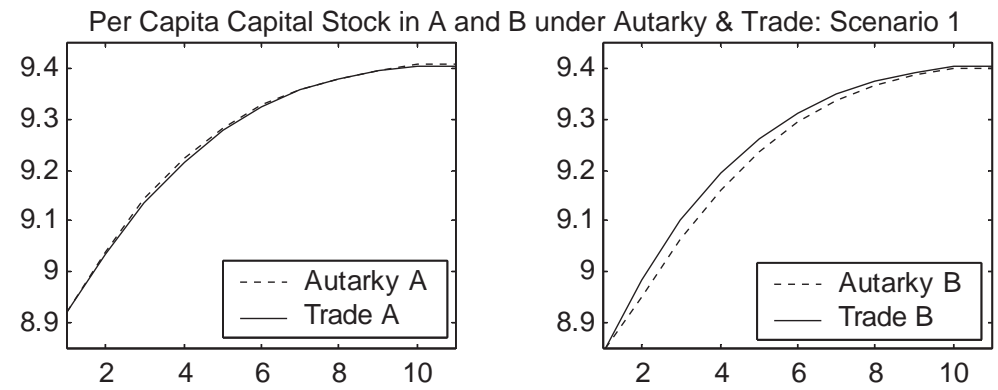

Per Capita Capital Stock in A and B under Autarky \& Trade: Scenario 2
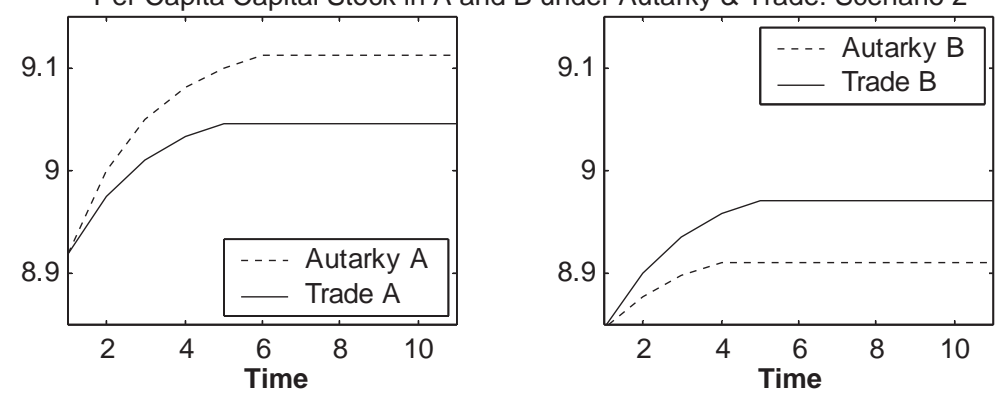

Fig. 7. Per capita capital stock values under autarky and trade over time.

As a result of these changes in relative commodity and factor prices, per capita GNP in region $A$ falls below and that in region $B$ jumps above their respective autarky levels under both scenarios. While the losses of $A$ and gains of $B$ get gradually eliminated toward the long-run equilibrium under Scenario 1, they remain distinctly visible under Scenario 2. In other words, Scenario 1 shows that region $B(A)$ gains (loses) from trade in the short- to medium-run, but its per capita GNP gains (losses) do not endure in the long run when both regions reach zero population growth once again as simulated under autarky (Fig. 8).

These changes in income levels affect consumption patterns, and hence per capita welfare levels as measured by the lifetime utility of the representative individual in Eq. (13). The picture for the welfare effects of trade is similar to the case of the effects on per capita GNP. As would be expected from the foregoing discussion, trade would not produce any welfare gains for region $A$ under either scenario. In fact, this region would be made worse off by trade, whereas region $B$ obtains temporary (permanent) gains that disappear in the long run under Scenario 1 (Scenario 2). Symmetrically, the losses of the low-population growth region $A$ are much smaller and transitional under Scenario 1 (Fig. 9).

The long-run results obtained under the two demographic scenarios are summarized in Table 2, which ranks steady-state autarky and trade values of key variables in a descending order (from left to right).

Three conclusions can be drawn concerning the rankings in Table 2. First, despite the visible differences in the magnitudes of resulting steady-state values, the rankings 
GNP per Capita in A and B under Autarky and Trade: Scenario 1

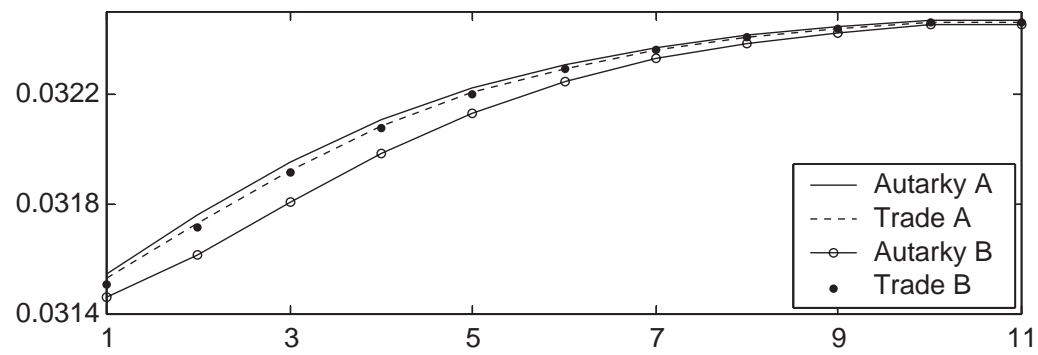

GNP per Capita in A and B under Autarky and Trade: Scenario 2

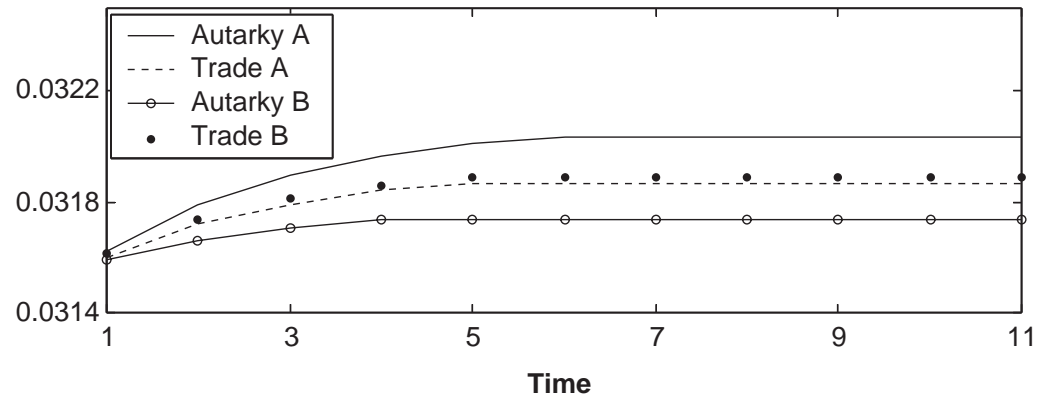

Fig. 8. Per capita GNP in regions $A$ and $B$ under autarky and trade.

Per Capita Welfare in A and B under Autarky and Trade: Scenario 1

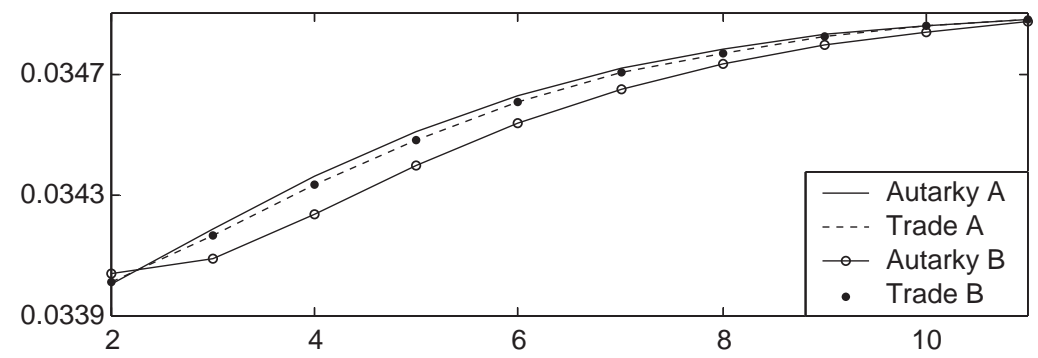

Per Capita Welfare in A and B under Autarky and Trade: Scenario 2

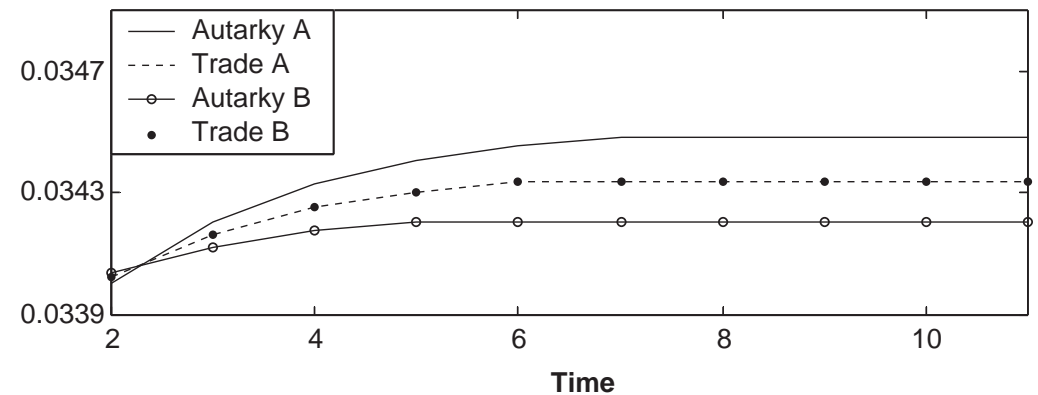

Fig. 9. Utility in regions $A$ and $B$ under autarky and trade. 
Table 2

Ranking of long-run equilibrium values of key variables in regions $A$ and $B$ under autarky and trade: Scenarios 1 and 2

\begin{tabular}{|c|c|c|c|c|}
\hline Steady state value of & Highest & Higher & Lower & Lowest \\
\hline$k$ & $A$ under autarky & $A$ under trade & $B$ under autarky & $B$ under autarky \\
\hline$r$ & $B$ under autarky & \multicolumn{2}{|c|}{$A=B$ under trade } & $A$ under autarky \\
\hline$w$ & $A$ under autarky & \multicolumn{2}{|c|}{$A=B$ under trade } & $B$ under autarky \\
\hline$p$ & $A$ under autarky & \multicolumn{2}{|c|}{$A=B$ under trade } & $B$ under autarky \\
\hline$u$ & $A$ under autarky & \multicolumn{2}{|c|}{$A=B$ under trade } & $B$ under autarky \\
\hline
\end{tabular}

of the key variables considered do not change across demographic scenarios. Secondly, the rankings are compatible with the expectations formed based on the closed-form solutions as discussed before. Third, a comparison of the rankings in Table 2 with the previously reported results in Sayan and Uyar (2001) and Sayan $(2002,2003)$ indicates that the results here are quite robust to changes in the values of parameters and initial conditions given in Table 1. In other words, the rankings in Table 2 are preserved for a wide range of parameter values and initial conditions, even though these affect the magnitude of long-run equilibrium values of variables and the paths leading to the long-run equilibrium. One must note also that these rankings remain similar between the first period when relative abundance of factors were first differentiated by unequal population growth rates, and the steady state due to the monotonous nature of the transition from initial to long-run equilibrium.

\section{Conclusions}

This paper addressed a largely overlooked issue in the dynamic trade literature by considering the role that differences in the speed of population growth across regions may play as determinants of dynamic comparative advantages within a HeckscherOhlin (HO) framework. For this purpose, the paper investigated the implications for trade of regional differences in population dynamics through the closed-form solutions and simulation results obtained within an overlapping generations general equilibrium framework with two commodities and two factors. To consider an HO world, the consumers populating each region were assumed to have exactly the same preferences over two goods requiring different capital intensities to produce, though the production technology employed for each good is the same across regions. It was further assumed that the regions were endowed with the same amounts of capital and labor initially, but relative factor endowments were allowed to get differentiated across regions over time due to regional differences in the way that populations (and hence, labor supplies) evolve. These demographic differences were introduced through two scenarios. Under the first scenario, population growth rates, $n_{t}^{A}$ and $n_{t}^{B}$, were assigned different initial values and allowed to decline at differing speeds across countries. The second scenario considered distinct but constant population growth 
rates for each region. The OLG-GE framework enabled to capture the additional changes in relative factor endowments to be observed due to the resulting differences in the rates of population aging, and hence, saving and capital accumulation behavior.

The implications of unequal population dynamics for trade patterns were first explored through closed-form solutions yielding steady-state values of key variables, and the behavior of different variables over time was then captured through numerical simulations carried out using a 2-factor, 2-commodity and 2-region dynamic model of international trade.

Both the analytical solutions and the numerical simulation exercises showed that the inequality of population growth rates would create à la Heckscher-Ohlin differences in relative factor endowments, with the slower population growth region becoming relatively capital-abundant and the faster population growth region becoming relatively labor-abundant over time. These would give rise to differences in autarky relative prices, creating grounds for trade as in the static HO model.

On the basis of an overall comparison, however, not all the results obtained under trade turned out to be consistent with the static HO framework. The country that is relatively abundant in one of the factors specializes in the production of the commodity which uses that factor more intensively and exports that commodity, and trade leads to an equalization of factor prices as predicted by the static HO model. Contrary to those predictions, however, trade would not necessarily represent a Pareto improvement over the state of autarky. While the static HO theory rules out welfare losses for either of the countries, the results in this paper revealed that trade may be immiserizing for the country whose population grows slowly relative to the other.

This is a significant finding which provides support to previous studies pointing out that welfare implications of trade predicted from the standard HO model might not be preserved under different dynamic setups. Furthermore, the results here offer the inequality of population growth rates across trading nations as a possible and previously unreported reason explaining why and how trade may not be Pareto superior to autarky.

In general, the analysis here lays the initial grounds for a rich discussion on possible consequences of the differential speed of demographic transition, fertility decline and population aging currently observed in various parts of the world. The introduction of the overlapping generations structure to the $2 \times 2 \times 2$ general equilibrium framework of the $\mathrm{HO}$ model made the model developed here particularly suitable for analyzing the consequences of projected changes in relative factor endowments in the capital-abundant countries with low and fast declining population growth rates and aging populations vis-a-vis the labor-abundant countries with high and slowly declining population growth rates.

While the assumption that both regions use identical production technologies for each commodity they produce was employed to recreate the HO world, it presumably affects the relevance of results for real-life situations. Yet, given the ease of transferring production technologies, one can still conclude that differential speeds of population increases are indeed likely to become major determinants of 
trade and factor flows in the decades ahead, since the changing sizes of labor forces and age profiles of populations affect relative abundance of labor and capital.

The OLG framework described in this paper facilitates modeling the effects of demographic differences on the evolution of relative factor endowments, and the resulting patterns of trade and factor flows. Suggestions for future research include the introduction of capital mobility and migration to the trade model, and repeating the analysis here by endogenizing population growth rates so as to link the slow down in the speed of population increases to income growth over time, as observed in real life. Such extensions will certainly provide additional insights into the possible nature of economic relations between countries across which the timing of demographic transition differs considerably, and increase the policy relevance of results from simulation exercises.

\section{Acknowledgements}

The author greatly appreciates comments on earlier versions of this paper by two anonymous referees; Larry Kotlikoff, Michel Juillard and other participants at the Seventh International Conference of the Society for Computational Economics, as well as seminar participants at Bilkent, Bogazici, Middle East Technical, Ohio State, Sabanci and West Virginia Universities and the University of California, Riverside.

\section{References}

Auerbach, A.J., Kotlikoff, L.J., 1987. Dynamic Fiscal Policy. Cambridge University Press, Cambridge. Buiter, W.H., 1981. Time preference and international lending and borrowing in an overlappinggenerations model. Journal of Political Economy 89 (4), 769-797.

Chen, Z., 1992. Long-run equilibria in a dynamic Heckscher-Ohlin model. Canadian Journal of Economics 25, 923-943.

Deardorff, A.V., 1987. Trade and capital mobility in a world of diverging populations. In: Johnson, D.G., Lee, R.L. (Eds.), Population Growth and Economic Development: Issues and Evidence. University of Wisconsin Press, Madison, MI.

Diamond, P.A., 1965. National debt in a neoclassical growth model. American Economic Review 55, 1126-1150.

Eaton, J., 1987. A dynamic specific-factors model of international trade. Review of Economic Studies 54 (2), 325-338.

Findlay, R., 1970. Factor proportions and comparative advantage in the long run. Journal of Political Economy 78 (1), 27-34.

Fried, J., 1980. The intergenerational distribution of the gains from technical change and from international trade. Canadian Journal of Economics 13 (1), 65-81.

Galor, O., 1988. Is free trade indeed optimal for a small economy? A dynamic general equilibrium analysis. Department of Economics Working Paper No. 88-8, Brown University, Providence, RI.

Galor, O., 1992. A two-sector overlapping generations model: global characterization of the dynamical system. Econometrica 60, 1351-1386.

Galor, O., Lin, S., 1994. Terms of trade and current account dynamics: a methodological critique. International Economic Review 35 (4), 1001-1014. 
Galor, O., Lin, S., 1997. Dynamic foundations for the factor endowment model of international trade. In: Jensen, B.S., Wong Dynamics, K. (Eds.), Dynamics, Economic Growth, and International Trade (Studies in International Economics). University of Michigan Press, Ann Arbor, MI.

Guilló, M.D., 2001. The trade balance and the terms of trade in a two-country two-sector OLG economy. Spanish Economic Review 3 (1), 71-80.

Holtz-Eakin, D., Lovely, M.E., Tosun, M.S., 2004. Generational conflict, fiscal policy, and economic growth. Journal of Macroeconomics 26 (1), 1-23.

INGENUE Team, 2001. INGENUE: an applied international overlapping generations model. Paper Presented at the IFAC Symposium on Modeling and Control of Economic Systems, Klagenfurt, September 6-8.

Jelassi, M.M., Sayan, S., 2003. Implications of unequal rates of growth for trade. Department of Economics Discussion Paper No. 03-02, Bilkent University, Ankara.

Jelassi, M.M., Sayan, S., 2004. Population growth differentials and the long-run trade equilibrium. Journal of Population Economics, forthcoming.

Kenc, T., Sayan, S., 2001. Demographic shock transmission from large to small countries: an overlapping generations CGE analysis. Journal of Policy Modeling 23 (6), 677-702.

Miles, D., 1999. Modelling the impact of demographic change upon the economy. Economic Journal 109 , $1-36$.

Mountford, A., 1998. Trade, convergence and overtaking. Journal of International Economics 46, $167-182$.

Oniki, H., Uzawa, H., 1965. Patterns of trade and investment in a dynamic model of international trade. Review of Economic Studies 32, 15-38.

Sayan, S., 2002. Dynamic Heckscher-Ohlin results from a $2 \times 2 \times 2 \times 2$ overlapping generations model with unequal population growth rates. Department of Economics Discussion Paper No. 02-01, Bilkent University, Ankara.

Sayan, S., 2003. Trade and labor flows between countries with young and aging populations. In: Neck, R. (Ed.), Modeling and Control of Economic Systems 2001. Elsevier Science, Amsterdam.

Sayan, S., Uyar, A.E., 2001. Directions of trade flows and labor movements between high- and lowpopulation growth countries: an overlapping generations general equilibrium analysis. Department of Economics Discussion Paper No. 01-08, Bilkent University, Ankara.

Solow, R.M., 1956. A contribution to the theory of economic growth. Quarterly Journal of Economics 70, 65-94.

Tosun, M.S., 2003. Population aging and economic growth: political economy and open economy effects. Economics Letters 81 (3), 291-296.

UN, 2001. World population prospects: the 2000 revision highlights. Population Division Report No. ESA/P/WP.165, United Nations, New York. 